\title{
CONTROL SYSTEM OF STEEL BATTERY CHARGER
}

UDC ((621.3.077.5+621.43.044.7):681.518.52)

\author{
Nikola Danković ${ }^{1}$, Dragan Antić ${ }^{1}$, \\ Zoran Icić ${ }^{1}$, Stanko Stankov ${ }^{1}$, Dejan Mitić ${ }^{1}$, Marko Živković ${ }^{2}$ \\ ${ }^{1}$ University of Niš, Faculty of Electronic Engineering, Department of Control Systems, \\ Niš, Republic of Serbia \\ ${ }^{2}$ University of Niš, University Computer Center, Niš, Republic of Serbia
}

\begin{abstract}
A practical realization of control of a diode-thyristor bridge is provided in this paper. The proposed control logic is applied to an NiCd accumulator charger. These accumulators are used for power supply of electrical devices and equipment in CFR locomotives. The control system provides a regular mode of NiCd accumulators charging and discharging, and, in this way, their long lifespan. A hardware configuration and a control algorithm for efficient NiCd accumulator charging and preventing overcharging and overheating are provided.
\end{abstract}

Key words: steel accumulator, charger, control logic, thyristor, ignition angle

\section{INTRODUCTION}

Steel (NiCd) batteries are reliable sources of electricity and they have various good performances: long lifespan, wide range of operating temperatures, resistance to mechanic and electric loads, high discharge currents. These batteries also do not generate corrosive gasses, they are can be recharged rapidly, and they are very easy for maintenance. It has been shown that this type of batteries retain service performances even during a multiyear storage without electrolyte and for the electricity empty state. From the aspect of environmental protection $\mathrm{NiCd}$ batteries are a green source of energy because $99 \%$ metal for construction of batteries can be recycled [1].

Steel $(\mathrm{NiCd})$ batteries are widely used in the systems with required permanent power supply (diesel and electrical locomotives, motor trains, trams, trolleybuses, etc.). Accumulators with lamellar electrodes [2] are usually used in such systems. A typical characteristic of KPL series accumulators (low discharge rate cells) is shown in Fig. 1. The nominal voltage of the battery (operating voltage) is $1.2 \mathrm{~V}$. The nominal capacity of the

Received September 10, 2017

Corresponding author: Nikola Danković

Faculty of Electronic Engineering, Aleksandra Medvedeva 14, 18000 Niš, Republic of Serbia

E-mail: nikola.dankovic@elfak.ni.ac.rs 
battery is the five-hour capacity (C5) at the temperature $20 \pm 5^{\circ} \mathrm{C}$. Nominal charge/discharge current is: $\mathrm{I}=0.2 \mathrm{C} 5 \mathrm{~A}$.

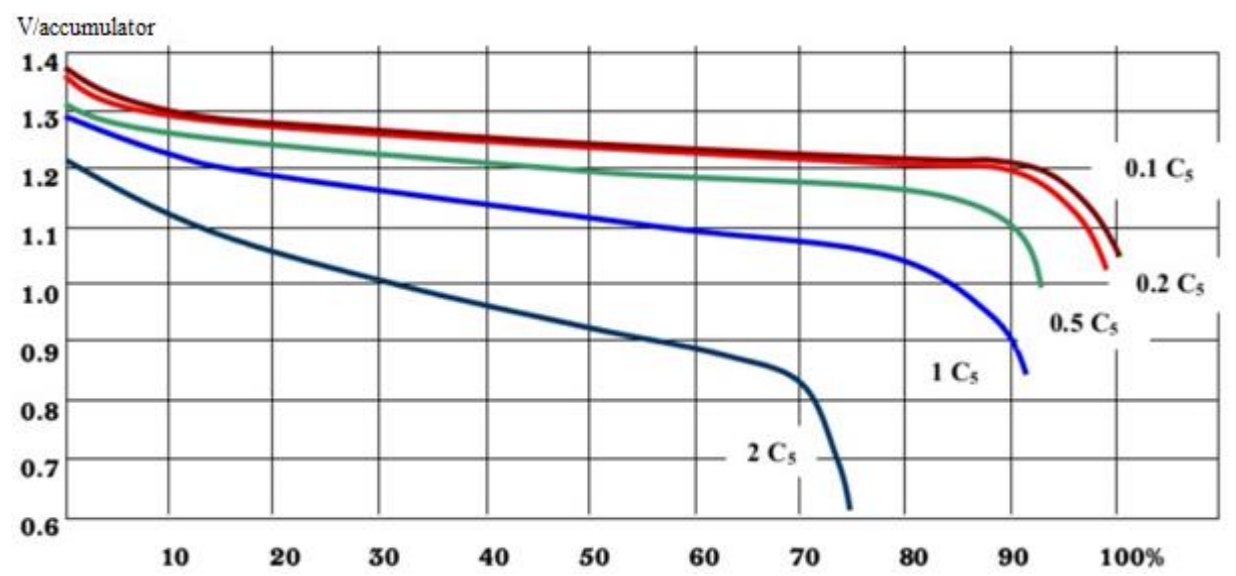

Fig. 1 Typical discharge characteristic of KPL accumulators at $20^{\circ} \mathrm{C}$

Accumulator performances (lifetime, good battery usage, and operational readiness) mostly depend on a charging strategy and the rectifier-accumulator-receiver system. The simplest way is on/off charge and discharge of accumulators. A charger is usually a diode rectifier where the consumer is off during charging and the charger is off when the consumer is connected. A more efficient system is obtained when the controlled charger is inserted between the accumulator and the consumer [3].

A block diagram of the controlled charger (rectifier) of an $\mathrm{NiCd}$ accumulator is shown in Fig. 2. A power supply of a consumer within a locomotive (lighting, heating system, ventilation, air condition, communication, etc.) consists of a diode-thyristor bridge, an accumulator, a control unit, and an LCD module.

A rectifier is used for charging, monitoring, and keeping an $\mathrm{NiCd}$ accumulator in a charged state, and also for power supply of DC consumers at CFR type of electrical locomotives. An accumulator consists of $841.2 \mathrm{~V}$ voltage units connected in series. Voltage regulation is in the range of $100 \mathrm{~V}$ up to $126 \mathrm{~V}$, and current regulation is in the range of 7A up to 20A. The power supply of a diode-thyristor unit is led from the locomotive generator, i.e. from $\mathrm{AC} 1, \mathrm{AC} 2$ connectors. For one semi-period the thyristor $\mathrm{TH} 1$ and the diode D2 are conductive, and for another semi period the thyristor TH2 and the diode D1 are conductive [3]. A regulation circuit holds a constant output voltage of the thyristor unit by adjusting the thyristor ignition angle. The above mentioned voltage and current ranges can be extended from 0 up to $250 \mathrm{~V}$ and from 0 to $20 \mathrm{~A}$, respectively, by an appropriate power supply and choice of components of the diode-thyristor bridge. The LCD modules for monitoring of the set and current values of current and voltage are connected with control unit via an RS232 communication. 


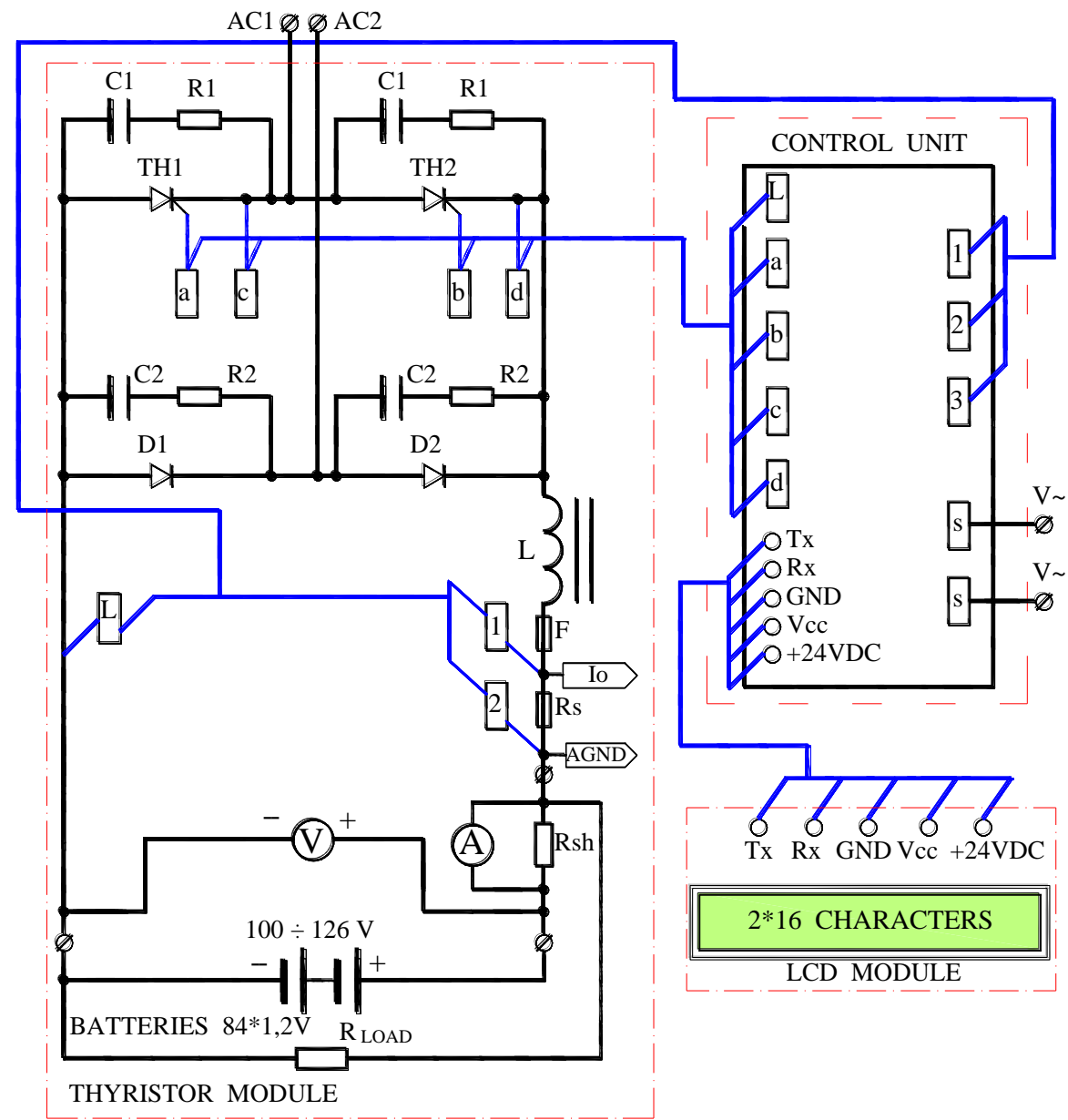

Fig. 2 A block diagram of charging an NiCd accumulator in the locomotive

\section{THE CONTROL SySTEM OF AN NICD ACCUMUlator CHARGER}

Rectifier control is performed by using ATmega8 microcontroller. A scheme of this controller is given in Fig. 3, and hardware realization in Fig. 4. It is a cheap component with "hardware concept" and AVR RISC architecture designed in CMOS technology, and it is well-known for its low consumption [4]. 


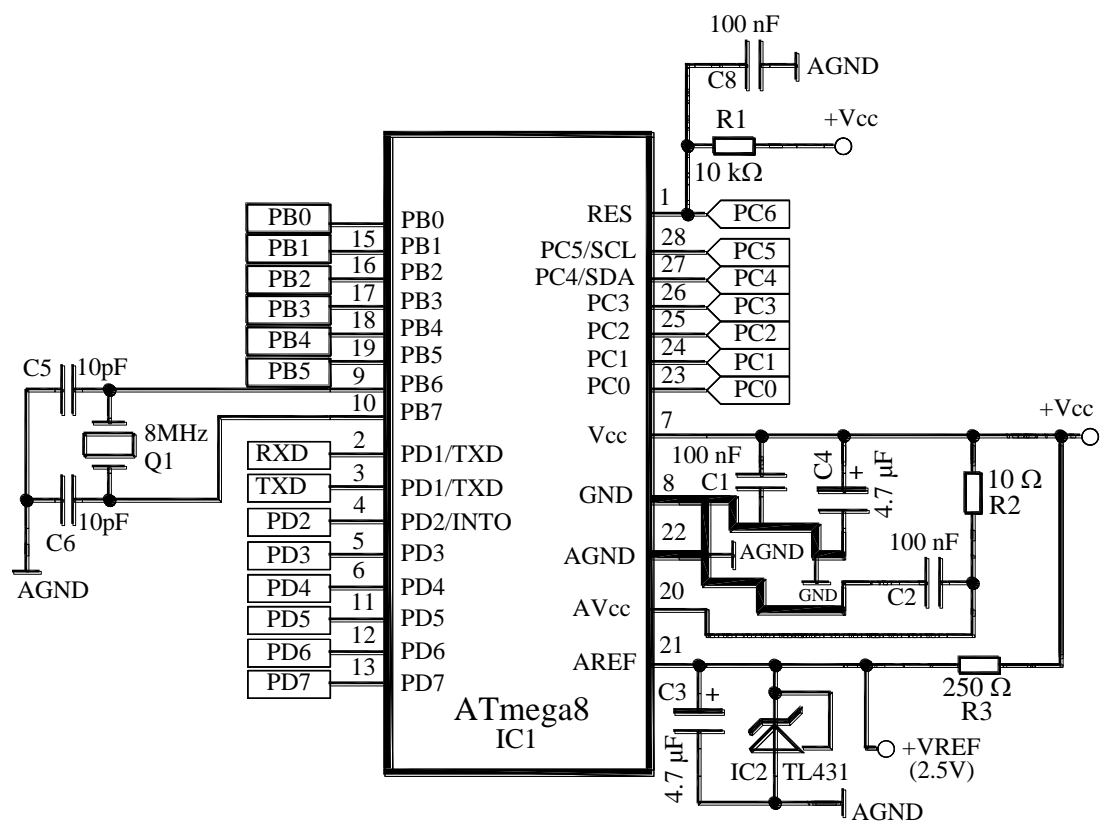

Fig. 3 A wiring diagram of ATmega8 microcontroller

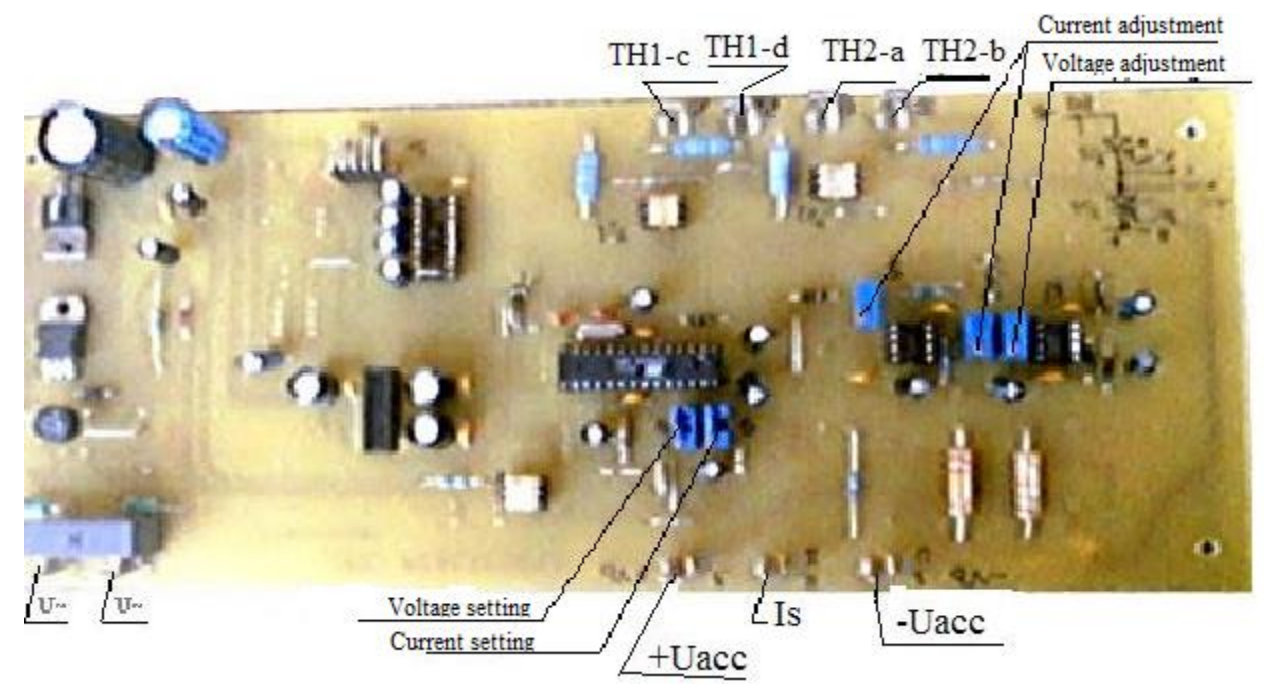

Fig. 4 Control logic hardware realization

ATmega8 microcontroller has $8 \mathrm{~KB}$ programming memory for program storage. It is a flash memory that, with an integrated ISP (In-System Programming) interface, significantly facilitates application development. Namely, this provides reprogramming microcontroller even when it is soldered on the board of the developing device. Beside 
programming the memory, the microcontroller has $1 \mathrm{~KB}$ static RAM memory for data storage, and 512B EEPROM memory whose role is to store data that must not be lost when there is no voltage supply. Programming FLASH memory is organized as $4 \mathrm{~K}^{*} 16$ bits, because commands at the AVR microcontroller are 16 or $32 \mathrm{~B}$. The Pipeline mechanism, which allows downloading the next instruction during the execution of the previous one, is integrated, as well. The concept of the RISC architecture and pipeline mechanism provides that each instruction is executed in one interval of the system tact. An important characteristic of an AVR microcontroller is that frequencies of a tact and oscillator, used for generating pulses, are equal. It means that the ATmega8 processor on $16 \mathrm{MHz}$ has a speed of $16 \mathrm{MIPS}$, which is very good for 8-bit processors [4, 5].

AVR microcontrollers have 32 8-bit registers of general purpose. Each register can be used as an accumulator in executing arithmetic operations, wherein there are some restrictions of usage of certain registers for some instructions. Registers are mapped in SRAM memory at first 32 addresses. At next 64 addresses the I/O registers of peripheral microcontroller units are mapped. Intern SRAM memory starts from address $60 \mathrm{H}$. ATmega8 microcontroller has three I/O ports: port B with eight derived pins on the processor case, port $\mathrm{C}$ with seven pins, and port $\mathrm{D}$ with eight pins. Each pin has multiplexed additional functions depending on which the peripheral unit is used. For example, on port $\mathrm{C}$ pins, analogue inputs of $\mathrm{A} / \mathrm{D}$ convertor are located.

Pins can be configured as either input or output, independently of how other pins of the same port are configured. Pins PB1, PB0 trigger optothyristors TH1.1 and TH1.2, and galvanic separated pulses are sent in this way (Fig. 5).

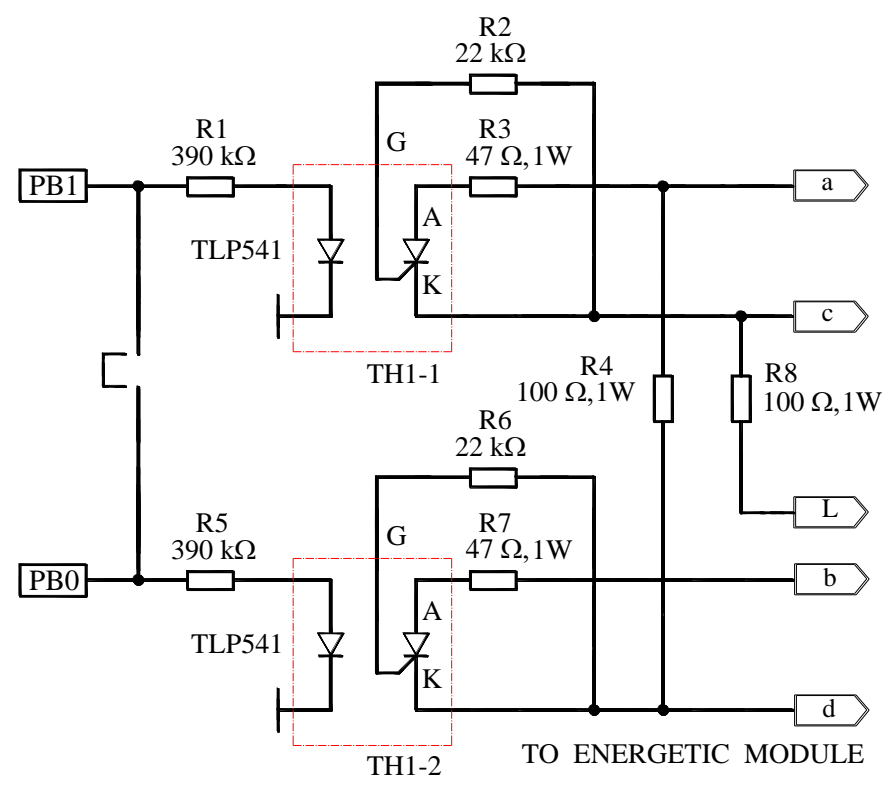

Fig. 5 Galvanic isolated signals for thyristor ignition in the rectifier 
Optothyristors open gates of energetic thyristor TH1, TH2 of a diode-thyristor bridge are shown in Fig. 2.

Power supply with zero-crossing detection of control unit and following electronics is taken from a voltage source given in Fig. 6 [4].

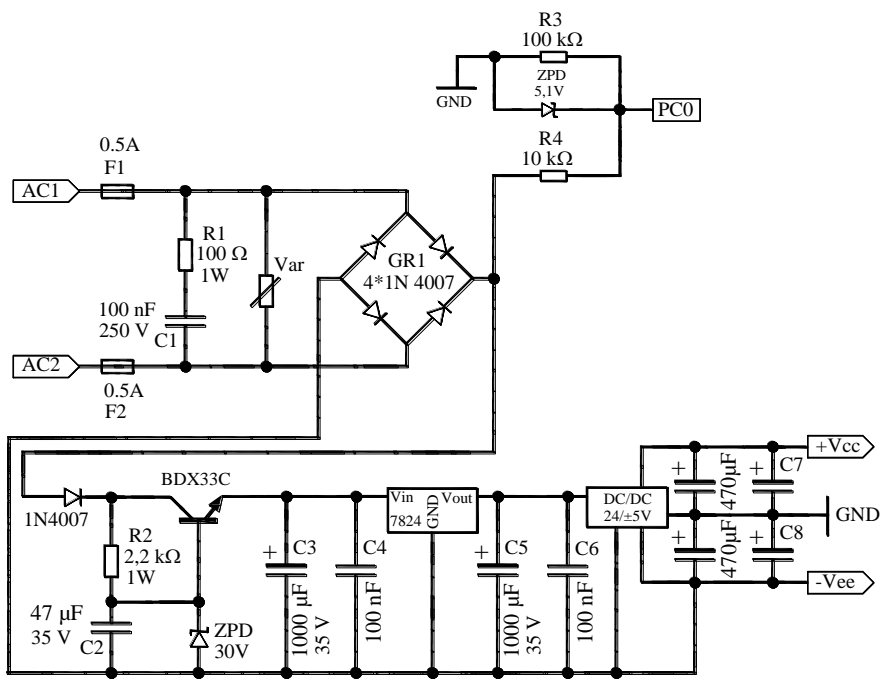

Fig. 6 A scheme for rectifier power supply

This is a classical configuration with diodes, serial transistor, stabilized integrated source 7824, integrated DC/DC converter, and a certain number of passive components.

A voltage oscillogram on the rectifier output, in the case of resistor load, is shown in Fig. 7. Voltage level depends on the thyristor ignition angle.
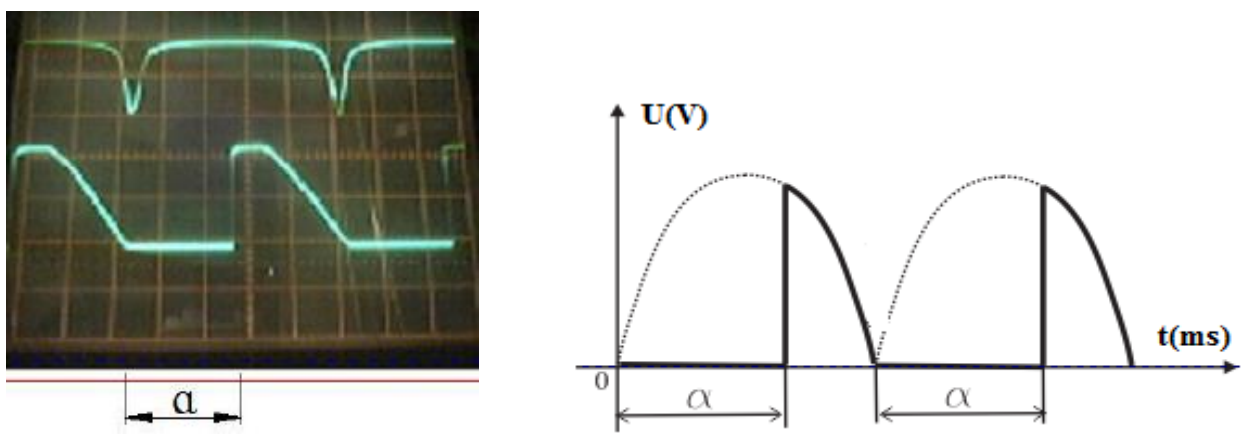

Fig. 7 Wave form of the rectifier voltage output 


\section{VOLTAGE AND CURRENT ADJUSTMENT}

Data from a thyristor rectifier (voltage and current) have to be reduced to appropriate level before input to a microcontroller. For this purpose, voltage (Fig. 8) and current transducer (Fig. 9) are used.

Battery voltage $\mathrm{U}_{\mathrm{o}}=-\mathrm{U}_{\mathrm{b}}$ can be in the range of $0 \div 250 \mathrm{~V}$. Intern 10 -bit $\mathrm{A} / \mathrm{D}$ converter of the used microcontroller is appropriate in the sense of resolution and accuracy (1023 points on the scale are sufficient in this case). Because of the referent processor voltage is $2.56 \mathrm{~V}$ and $\mathrm{A} / \mathrm{D}$ converter is 10 -bits, we have $2560 \mathrm{mV} / 2^{10}=2.5 \mathrm{mV}$ per bit, so $1 \mathrm{~V}$ is coded with 4 bits, i.e. $10 \mathrm{mV}$ on the A/D converter output. Therefore, input voltage has to be reduced in this range $(250 \mathrm{~V} / 10=2.5 \mathrm{~V})$ [4]. Via voltage divider R1-R2 the voltage $\mathrm{U}_{\mathrm{o}}$ is reduced with factor 10 (Fig. 8). This voltage is led to the inverting amplifier. The voltage is led from the amplifier output to the potentiometer P1 that precisely adjusts the value.

The voltage signal is led from the potentiometer via filter R6-C4 to the microcontroller pin PC3 [4]. The adjustment is performed by measuring voltage $\mathrm{U}_{\mathrm{o}}$, and by potentiometer P1 which adjusts voltage on the LCD display with the value of the rectifier voltmeter.

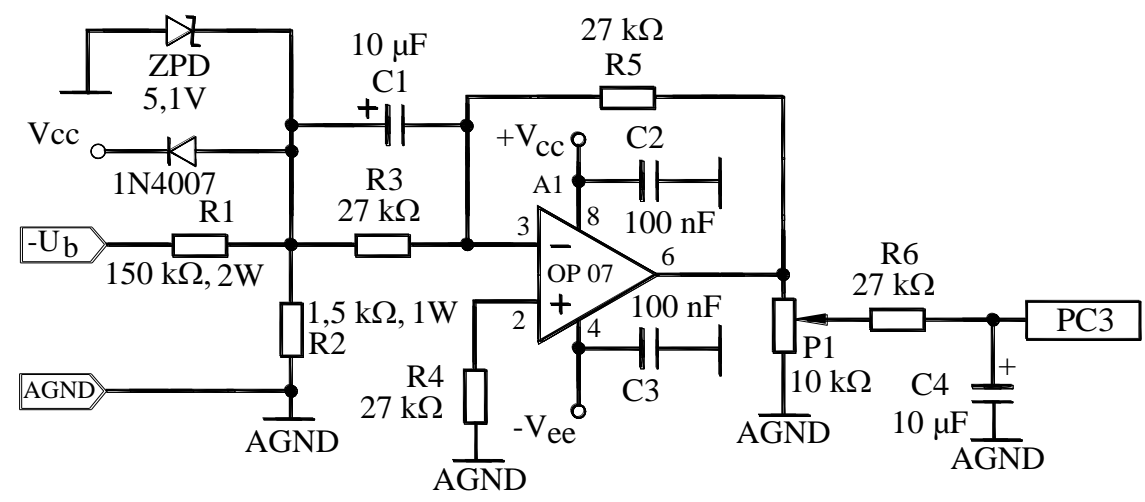

Fig. 8 Voltage transducer

A circuit for current adjustment within a control unit is shown in Fig. 9 [6]. The resistor of current sensor $R_{s}$ is $2.5 \mathrm{~m} \Omega$ (Fig. 2). One bit corresponds to 0.1A, i.e. $2.5 \mathrm{mV}$.

The voltage on the sensor resistor is $2.5 \mathrm{~m} \Omega * 0.1 \mathrm{~A}=0.25 \mathrm{mV}$. There is a need for amplification of $A=10 \mathrm{mV} / 0.25 \mathrm{mV}=40$ for conversion $0.1 \mathrm{~A}$ to $10 \mathrm{mV}$. The amplification is adjusted via potentiometers $\mathrm{P} 1$ and $\mathrm{P} 2$, and the resistor $\mathrm{R} 2$. The current is measured by an instrument installed on the rectifier, and adjustment is done by a potentiometer. If the value of sensor resistor $R_{\mathrm{s}}$ is different, it needs to be adjusted appropriately. For example, for $R s=50 \mathrm{~m} \Omega$, the voltage is $U_{s}=R_{s} I_{o}=50 m \Omega * 0.1 A=5 m V$. Because the current value of $0.1 \mathrm{~A}$ corresponds with $10 \mathrm{mV}$, the required signal amplification is: $A=U_{p c 3} / U_{s}=10 \mathrm{mV} / 5 \mathrm{mV}=2[4,6]$. The signal is led from this circuit output onto the microcontroller pin PC4. 


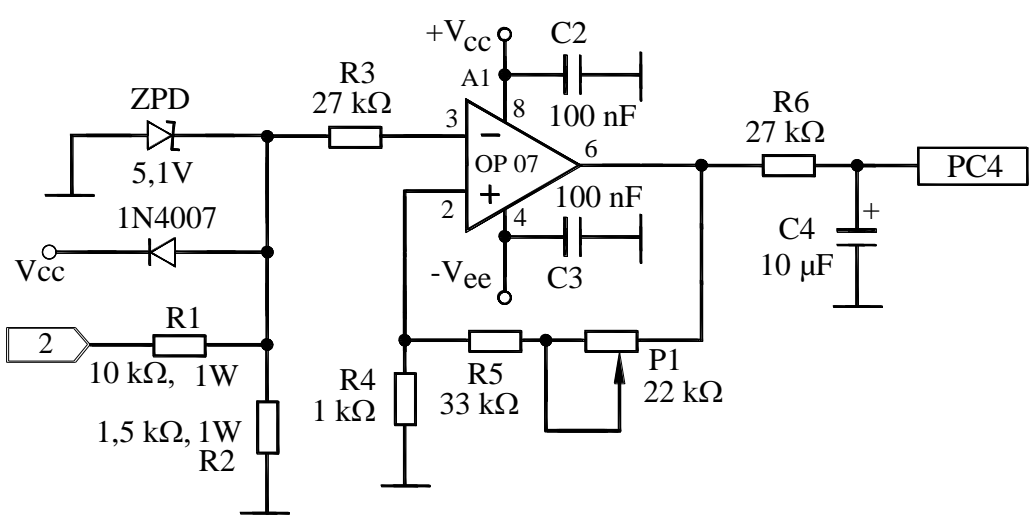

Fig. 9 Current transducer

\subsection{Voltage and current setting}

Setting voltage and current is done by voltage dividers (Fig. 10). From these dividers voltage signals are led via RC filters onto the microcontrollers pins (PC1 - voltage setting, PC2 - current setting). These values are compared with the present measuring values in the algorithm.

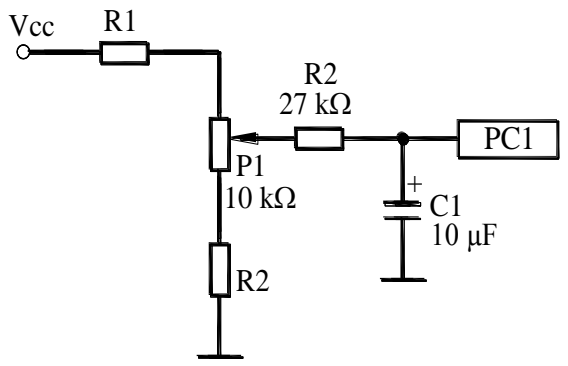

a)

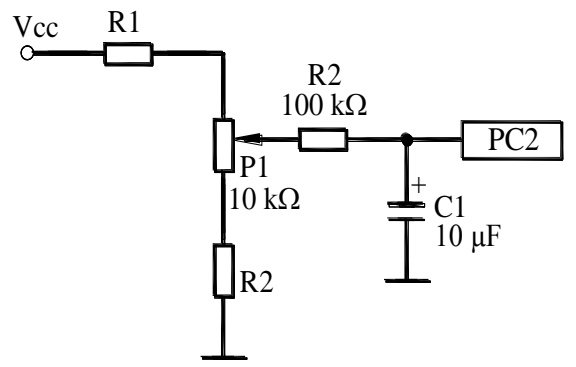

b)

Fig. 10 a) setting voltage, b) setting current

\section{CONTROL ALGORITHM}

Control strategy of voltage in locomotive batteries is based on the changes of the thyristor ignition angle in the rectifier. The ignition angle is time from the moment of $\mathrm{A} / \mathrm{C}$ voltage zero crossing (from the locomotive generator) until the moment of thyristor ignition. In the moment of turn on, the ignition angle is set on the maximum value $(250 * 40 \mathrm{~ms})$. It is the moment at the end of the semi-period, so thyristors are a bit open. Calculation of the ignition angle is performed for each semi-period. Voltage $U_{\text {set }}$ and current $I_{\text {set }}$ are set, and output voltage $U_{o}$ and output current $I_{o}$ are measured $\left(I_{0}=I_{s}\right.$; from sensor resistor $R_{s}$ voltage proportional to current $I_{0}$ is "removed"). The control is 
performed based on the set and measured values: if output current $I_{0}$ is less than set $I_{\text {set }}$ and voltage $U_{o}$ is less than $U_{\text {set }}$, the program reduces the thyristor ignition angle for 1 bit $(40 \mu \mathrm{s})$. This angle is constant for the next two semi-periods $(n=2)$. After $n$ semi-periods the ignition angle is again calculated in the previously described way. When $\mathrm{U}_{\mathrm{o}}=\mathrm{U}_{\text {set }}$, $I_{\text {set }}>I_{0}$ the microprocessor increases the ignition angle for 1 bit. In this way the output voltage is decreased. If in the next iteration $U_{0}<U_{\text {set }}$ the ignition angle is decreased for 1 bit to increase voltage. In this way, the output voltage $U_{o}$ is oscillating within the range $\pm 1 \mathrm{~V}$ around the set value. If $\mathrm{I}_{0}>\mathrm{I}_{\text {set }}$ then the ignition angle is increased for 1 bit that causes decreasing voltage. The procedure is continued until $\mathrm{I}_{\mathrm{o}} \leq \mathrm{I}_{\text {set }}$. Then, the condition $\mathrm{U}_{\mathrm{o}} \leq \mathrm{U}_{\text {set }}$ is checked, and if it is valid, the ignition angle is decreased for 1 bit that causes increasing voltage. In the next moment, if $\mathrm{I}_{\mathrm{o}}>\mathrm{I}_{\text {set }}$ the ignition angle is increased for 1 bit, etc. In the case, when there is no voltage in the thyristor (control unit), the control circuit decreases the ignition angle (maximal openness of a thyristor) to increase voltage. If in this moment maximal voltage level is reached, the control logic has a role to reduce it to the set level. This voltage reduction is performed in the following procedure: if $U_{\text {set }}>0, U_{0}=0, I_{0}=0$, the ignition angle $\alpha>50$ (the condition when there is no rectifier voltage), the processor sets a certain value for the ignition angle (e.g. $200 * 40 \mu$ s) instead of the minimum value. If there is a voltage on thyristors, the control is performed by the described algorithm. The wave forms of output rectifier voltage and current for resistance and battery load are given, respectively in Figs. 11, 12, and 13.
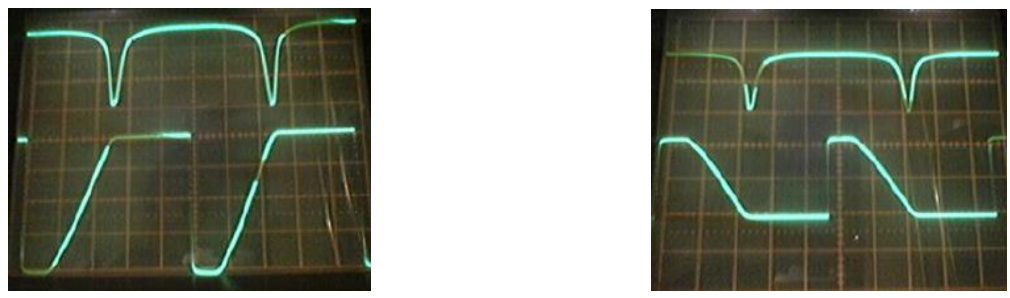

Fig. 11 Oscillogram of voltage and current for resistance load a) voltage on the load (minimum)

b) load current
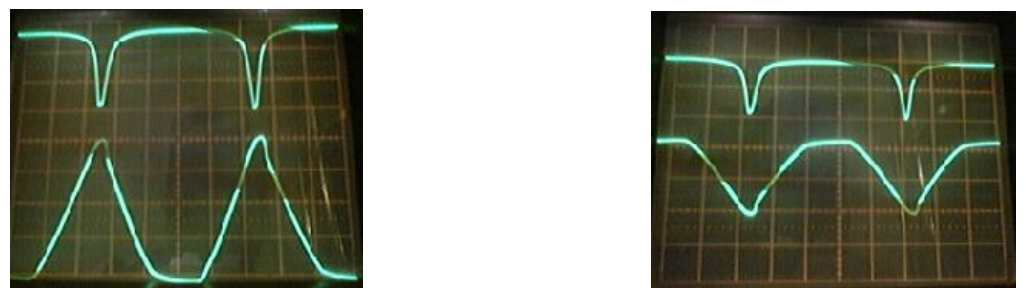

Fig. 12 Oscillogram of voltage and current for resistance load a) voltage on the load (minimal ignition angle)

b) load current 

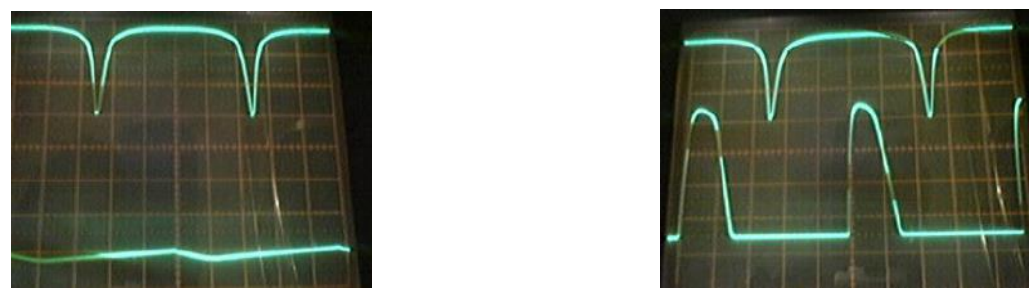

Fig. 13 Oscillogram of voltage and current for battery load a) voltage on the load

b) load current

\section{DisPlaying SET AND MEASUREd VALUES}

Displaying characteristic variables and parameters is provided via an LCD monitor ( $2 * 16$ characters) with an integrated controller and DDRAM (Display Data Random Access Memory) with capacity of $80 \mathrm{~B}$ (memory for 80 characters). CGRAM (Character Generator Random Access Memory) of 64B provides defining 8 characters in the form of $5 * 8$ pixel matrixes. CGROM (Character Generator Read Only Memory) includes predefined characters of 8320 bits. Display has a backlight. Hardware realization is shown in Fig. 14.

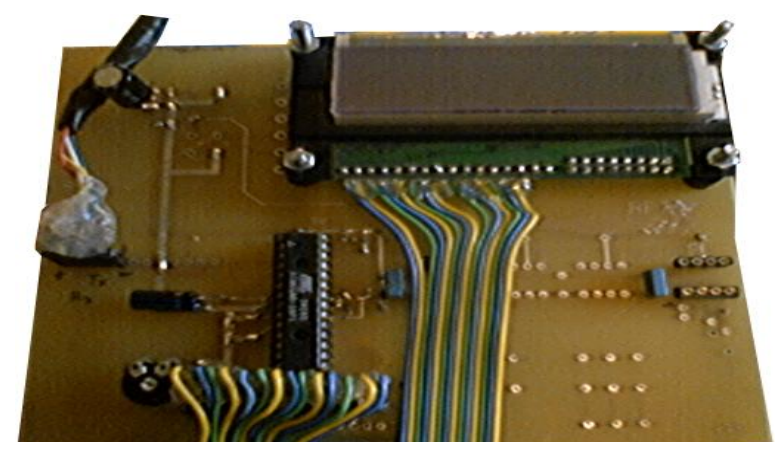

Fig. 14 LCD display hardware realization

An LCD module (Fig. 15) can communicate via 8-bit or 4-bit data bus depending on sending certain functional instructions during initialization. In the case of 8-bit Data Interface, data transfer is done at once via pins DB0 $\div$ DB7. In the case of 4-bit Data Interface, data transfer is performed in two steps via pins DB $4 \div$ DB7; firstly upper and then lower nibble is transferred. At the moment of turning on the voltage supply the LCD module automatically starts initialization process by an intern reset circuit. An LCD controller has 11 instructions which are actually combinations of bits on RS, R/W, and LCD data bus pins, when Enable pin on the level of a logic unit. 


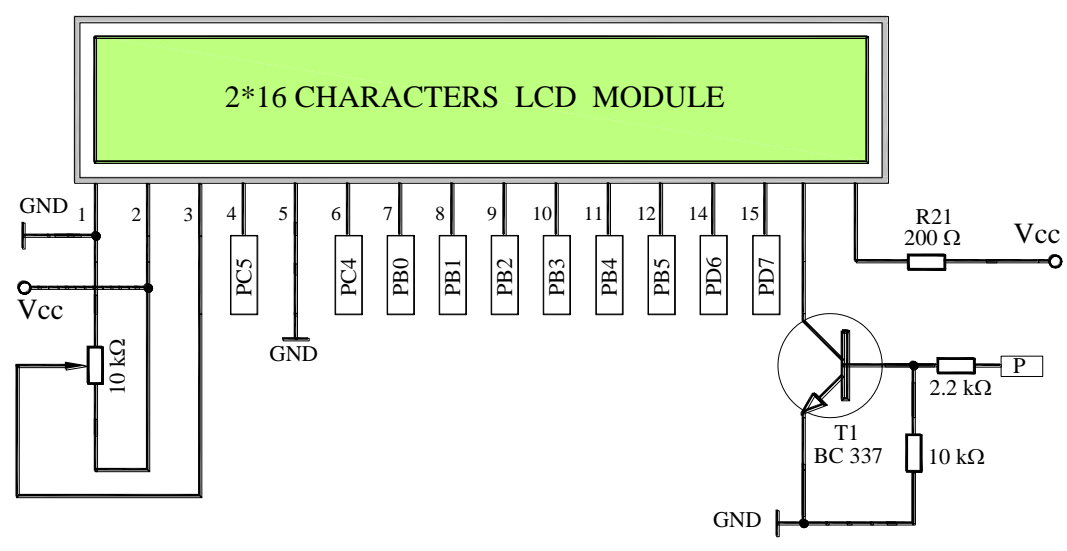

Fig. 15 LCD display scheme

An LCD module is realized in the following way. Firstly, RS and R/W signals are set on the appropriate level, then LCD data bus is set wherein this combination becomes valid by setting a pulse on Enable connector [4, 6].

The data of output voltage $U_{o}$, set voltage $U_{\text {set }}$, output current $I_{0}$, and set current $I_{\text {set }}$ are transferred via RS232 communication (Fig. 16) in the following way: in each semi-period (immediately before thyristor ignition) one piece of data is sent. Firstly, the code for OXEE synchronization is sent, and then $\mathrm{U}_{\text {set }}, \mathrm{U}_{\mathrm{o}}, \mathrm{I}_{\mathrm{set}}, \mathrm{I}_{\mathrm{o}}$ signals.

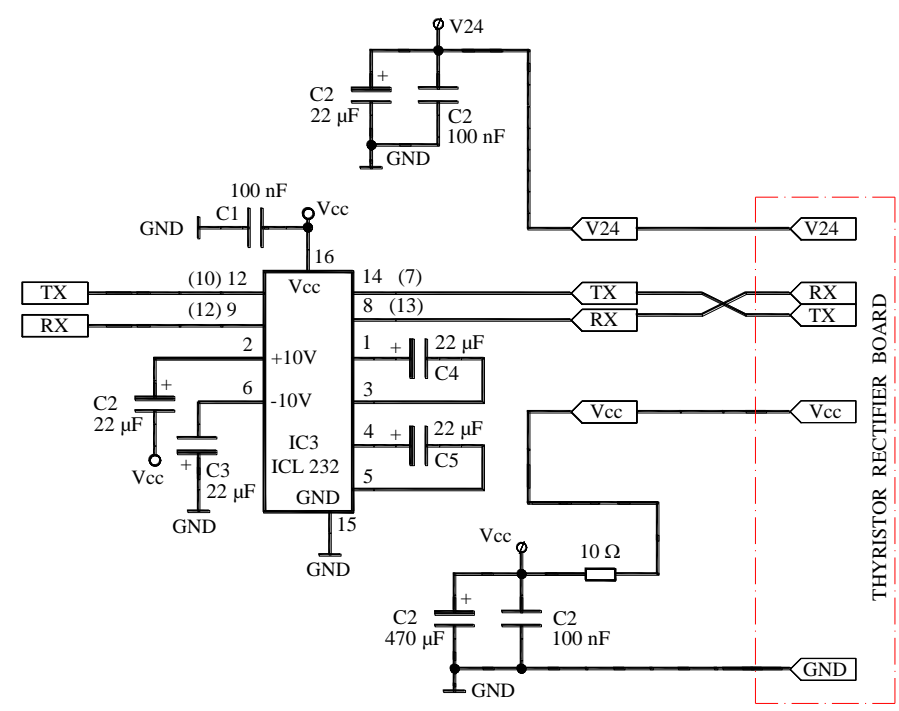

Fig. 16 RS232 communication 


\section{CONCLUSION}

In this paper, a regulation of a thyristor charger for $\mathrm{NiCd}$ accumulators that have wide range of applications (in this case CFR-type locomotive), is presented. The advantages of these accumulators are high reliability, long lifespan, temperature, mechanical and electrical stability, and easy maintenance. The control system is based on ATmega8 microcontroller. The control algorithm consists of measuring output current and voltage, and of comparing the obtained values with the ones set in advance. On the basis of this, the ignition angle is calculated. An integrated LCD display gives set and measured values of the current and voltage.

The control algorithm given in this paper was proved in practical realization as good enough. However, in some future work, it could be improved with some intelligent control as fuzzy logic or neural networks.

Acknowledgement: This paper was realized as a part of the projects "Studying climate change and its influence on the environment: impacts, adaptation and mitigation" (III 43007), and "Research and Development of New Generation Wind Turbines of High-energy Efficiency" (TR 35005), financed by the Ministry of Education and Science of the Republic of Serbia within the framework of integrated and interdisciplinary research for the period 2011-2018.

\section{REFERENCES}

[1] D. Linden, T. B. Ready, Handbook of batteries, McGraw-Hill, New York, 2002.

[2] S. Newman, K. E. Thomas-Alyea, Electrochemical Systems, 3rd ed., Englewood Cliffs: Prentice-Hall, 2004.

[3] R. Bernd, Maintenance-Free Batteries, 3rd ed., Overseas Press India, New Delhi, 2010.

[4] S. Stankov, Z. Icić, S. Nikolić, "Sawmill control device," in Proceedings of 23th International conf. process industry, Procesing, Tara, Serbia, pp. 151-158, 2010, (in Serbian).

[5] C. Kuhnel, AVR RISC Microcontroller Handbook, 1st ed., Newnes, 1998.

[6] H. Zumbahlen, Linear Circuit Design Handbook, Newnes/Elsevier, 2008. 